\title{
Standard Gibbs energies of transfer of halogenate and pseudohalogenate ions, halogen substituted acetates, and cycloalkyl carboxylate anions at the water|nitrobenzene interface
}

\author{
Rubin Gulaboski, Kai Riedl and Fritz Scholz* \\ Ernst-Moritz-Arndt-Universität Greifswald, Institut für Chemie und Biochemie, Soldmannstraße \\ 23,D-17489 Greifswald, Germany.E-mail: fscholz@uni-greifswald.de; Fax: +49 (0)383486 4451
}

Received 24th October 2002, Accepted 27th January 2003

First published as an Advance Article on the web 7th February 2003

The previously introduced three-phase electrode technique was used to determine the Gibbs energies of transfer of $\mathrm{ClO}_{3}{ }^{-}, \mathrm{BrO}_{3}^{-}, \mathrm{IO}_{3}^{-}, \mathrm{IO}_{4}^{-}, \mathrm{OCN}^{-}, \mathrm{SeCN}^{-}, \mathrm{CN}^{-}, \mathrm{N}_{3}^{-}$, halogen substituted acetate anions $\mathrm{Z}_{3-n} \mathrm{CH}_{n} \mathrm{COO}^{-}(\mathrm{Z}=\mathrm{F}, \mathrm{Cl}, \mathrm{Br}, \mathrm{I})$, and cycloalkyl carboxylate anions $\left(\left(\mathrm{CH}_{2}\right)_{n} \mathrm{COO}^{-}, n=3, \ldots, 7\right)$ at the water|nitrobenzene interface. Whereas the data for the small inorganic ions can easily be understood in terms of ion-dipole interactions, the data of the organic ions need consideration of charge delocalisation and its effect on the enthalpy and entropy of solvation.

\section{Introduction}

The partition of ions between two immiscible solvents plays a very important role in different chemical, pharmacological and biological areas. ${ }^{1-3}$ Standard Gibbs energies of transfer of ions between water and water immiscible solvents are fundamental data indicating their lipophilicity. They are often correlated with biological and pharmacological activity, such as adsorption, cell membrane permeability and hydrophobic binding. ${ }^{4,5}$ Although large and significant progress has been achieved in the last decade, ${ }^{6-20}$ standard Gibbs energies of transfer of many common inorganic ions are still not available. ${ }^{6}$ One reason for this situation are the limitations of the four-electrode technique. ${ }^{2}$ The four-electrode potentiostatic measurements at the interface of two immiscible electrolyte solutions (ITIES) provide a rather narrow window of $\Delta G$ values. The available potential window in these measurements is determined by the standard transfer potentials of the electrolyte ions present in the organic phase. When $\mathrm{TPhAs}^{+} \mathrm{TPhB}^{-}$(tetraphenylarsonium tetraphenylborate) is used as an electrolyte in the organic phase, theoretically, the available potential window ranges from -350 to $350 \mathrm{mV} .{ }^{2,6}$ However, in practise, this potential window is reduced to -300 to $+300 \mathrm{mV}$ or even less, as a result of earlier ascending currents. As a consequence, in some cases less reliable data have been reported in the literature, with values of $\Delta G$ falling close to the end of the potential window. Recent modifications in the four-electrode technique allowed an expansion of the potential window in ITIES experiments by measurements at microhole interfaces ${ }^{7-12}$ or indirectly by coupling of chemical equilibria in both phases. ${ }^{7,17-20}$ However, the non-polarizability of some organic solvents (e.g. n-octanol, menthol, etc.) or poorly defined interfaces between water and several organic solvents restrict the use of the four-electrode measurements to some organic solvents, mainly nitrobenzene, 1,2-dichlorethane, and nitrophenyl octyl ether. , $6,7,14-16,21,22^{2}$ Further, the application of the dropping electrolyte electrodes has produced data for which even the authors stated "an uncertainty of a few $\mathrm{kJ} \mathrm{mol}^{-1}$ ". ${ }^{23}$ These uncertainties are mainly due to the unreliable determination of polarographic half-wave potential as well as due to estimated data of diffusion coefficients and activity coefficients of the studied ions, parameters which are necessary to estimate the standard transfer potentials. ${ }^{23}$ Of course, more recently the data have been mainly obtained by linear sweep voltammetry or AC voltammetry, i.e. they are more reliable. ${ }^{2,6-22}$

The electrochemical technique introduced by one of $\mathrm{us}^{24}$ and successfully applied to a number of systems ${ }^{25-29}$ explores a so called "three-phase electrode" and conventional threeelectrode instrumentation. With this technique standard Gibbs energies for the water/nitrobenzene system can be determined in the range from -41 to $+37 \mathrm{~kJ} \mathrm{~mol}^{-1},{ }^{28}$ without coupling of solution equilibria. Moreover, the absence of an electrolyte in the organic phase and lifting of the restriction to polarized liquid-liquid interfaces allowed application of this technique to solvents with rather low dielectric constants, such as n-octanol, and even melts of L- and D-menthol. ${ }^{25,29}$ Here, we show that this technique allows also the determination of reliable and reproducible standard Gibbs energies of transfer of $\mathrm{ClO}_{3}{ }^{-}, \mathrm{BrO}_{3}^{-}, \mathrm{IO}_{3}^{-}, \mathrm{IO}_{4}^{-}, \mathrm{OCN}^{-}, \mathrm{SeCN}^{-}, \mathrm{CN}^{-}, \mathrm{N}_{3}^{-}$, of halogen substituted acetate ions, and cyclocarboxylate anions, and we discuss the factors determining these data.

\section{Experimental conditions}

A droplet of $2 \mu \mathrm{L}$ of a $0.1 \mathrm{~mol} \mathrm{~L}^{-1}$ solution of decamethylferrocene $(\mathrm{dmfc})$ (Acrös Organics) in water saturated nitrobenzene (NB) was attached to the surface of a paraffin impregnated graphite electrode (PIGE) by help of an Eppendorf-type pipette. The fabrication of the PIGE is described elsewhere. ${ }^{30}$ The electrode with the attached droplet was immersed into an aqueous electrolyte solution, and the electrochemical oxidation of $\mathrm{dmfc}$ in that three-phase arrangement was studied utilizing a three electrode potentiostat. Squarewave (SW) voltammetry was used for precise measurement of the peak potential, i.e. the formal potential of the system. Due to the short measurement time, the nitrobenzene droplet was stable and no distortion or change of the color of the droplet was observed. SW voltammograms were recorded using the commercial electrochemical measuring system AUTOLAB (PGSTAT 10, Eco-Chemie, Utrecht, The Netherlands). Typical instrumental parameters were: SW frequency $f=100 \mathrm{~Hz}$, 
SW amplitude $E_{\mathrm{sw}}=50 \mathrm{mV}$, scan increment $\mathrm{d} E=1 \mathrm{mV}$, and starting potential $E_{\mathrm{s}}=-0.50 \mathrm{~V}$ vs. $\mathrm{Ag} \mid \mathrm{AgCl}$. An $\mathrm{Ag}|\mathrm{AgCl}|$ saturated $\mathrm{NaCl}$ solution reference electrode $(E=0.200 \mathrm{~V}$ vs. SHE) was used and a platinum wire served as auxiliary electrode. All salts for preparation of the electrolyte solutions were used as purchased. All aqueous solutions were saturated with nitrobenzene. All chemicals used were of analytical grade and all were products of MERCK (Germany). The water used was Millipore Q. All experiments were carried out at $25^{\circ} \mathrm{C}$.

\section{Results and discussion}

Fig. 1 shows the situation at the three-phase electrode and the insets depict typical voltammograms when dmfc is oxidized at the "three-phase electrode" and anions are transferred from water to NB. Although the situation schematically depicted in Fig. 1 is discussed in details elsewhere, ${ }^{24-29}$ we briefly present here its major features in order to enable the reader to understand easier this approach. An electroactive and oxidizable highly hydrophobic neutral compound (e.g. decamethylferrocene $(\mathrm{dmfc}))$ is dissolved in an organic solvent (here nitrobenzene) immiscible with water which does not contain any deliberately added electrolyte. When a droplet of this solution is attached to the working electrode (here a paraffin impregnated graphite electrode (PIGE)) that is immersed in an aqueous electrolyte solution, then the electron transfer reaction occurring at the electrode|nitrobenzene interface has to be accompanied by ion transfer across the water|nitrobenzene interface in order to preserve the electro-neutrality of the organic phase (see Fig. 1). Because, initially, no electrolyte is present in the organic phase, the applied potential acts only at the "line" where all three phases meet, i.e., at the aqueous/organic/electrode three-phase junction. The redox reaction starts at that three-phase junction and advances toward the center of the droplet (see ref. 27 for instance). What kind of ion transfer will take place, i.e. transfer of anions from the aqueous phase into nitrobenzene, or transfer of the created $\mathrm{dmfc}^{+}$cations from nitrobenzene to water depends on the values of standard Gibbs energies of transfer of the anions and the $\mathrm{dmfc}^{+}$cations across the water|nitrobenzene interface. In any case, the electrode reaction of $\mathrm{dmfc}$ in nitrobenzene will be followed by the thermodynamically favored ion transfer. When the oxidation of $\mathrm{dmfc}$ in nitrobenzene is accompanied by a transfer of anions from water to nitrobenzene, the potential of the response is strongly dependent on the type and concentration of ions present in the aqueous phase.

The electrode process of dmfc oxidation in the $\mathrm{E}|\mathrm{NB}| \mathrm{W}$ three-phase arrangement can be described by the following reaction:

$$
\mathrm{dmfc}_{(\mathrm{NB})}+\mathrm{X}_{(\mathrm{W})}^{-} \leftrightarrows \mathrm{dmfc}_{(\mathrm{NB})}^{+}+\mathrm{X}_{(\mathrm{NB})}^{-}+\mathrm{e}^{-}
$$

The following form of the Nernst equation applies to this reaction: ${ }^{24,31}$

$$
\begin{aligned}
E_{\mathrm{c}}^{\ominus^{\prime}}= & E_{\mathrm{dmfc}^{+}{ }_{(\mathrm{NB})}\left[\mathrm{dmfc}_{(\mathrm{NB})}\right.}+\Delta_{\mathrm{W}}^{\mathrm{NB}} \varphi_{\mathrm{X}^{-}}^{\ominus}-\frac{R T}{F} \ln \left(a_{\mathrm{X}^{-}}{ }_{(\mathrm{W})}\right) \\
& +\frac{R T}{F} \ln \left(\frac{a^{*}{ }_{\mathrm{dmfc}_{(\mathrm{NB})}}}{2}\right)+\frac{R T}{F} \ln \frac{a_{\mathrm{dmfc}_{(\mathrm{NB})}}}{a_{\mathrm{dmfc}_{(\mathrm{NB})}}}
\end{aligned}
$$

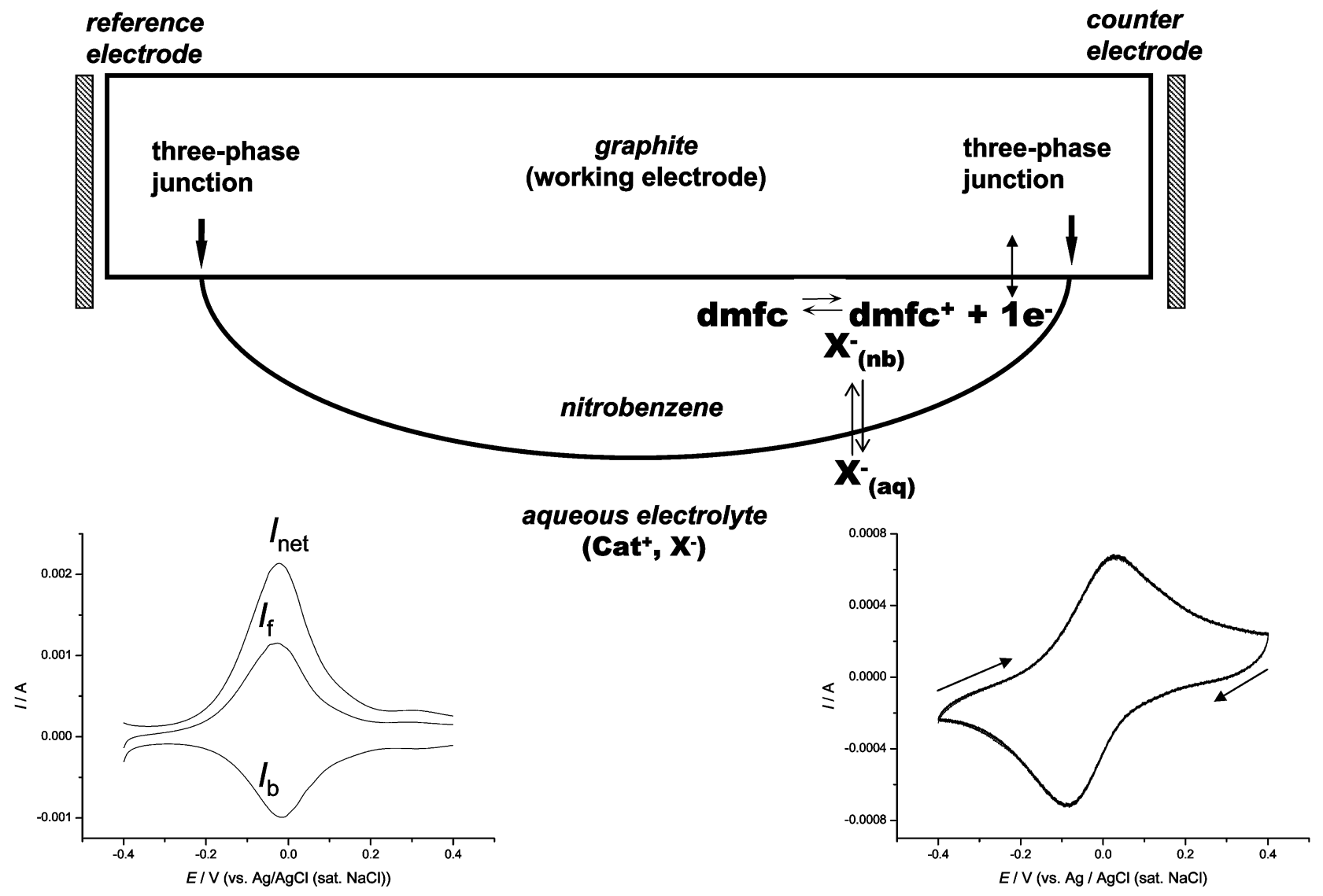

Fig. 1 Schematic representation of the three-phase electrode consisting of a nitrobenzene (NB) droplet containing decamethylferrocene (dmfc), which is attached to a graphite electrode and immersed in an aqueous salt solution. The insets show typical square-wave and cyclic (10 scans) voltammograms of a NB droplet containing $0.1 \mathrm{~mol} \mathrm{~L}^{-1} \mathrm{dmfc}$ that is attached to a graphite electrode and immersed in aqueous solutions containing 1 mol L ${ }^{-1} \mathrm{NaClO}_{3}$. The other conditions were: SW frequency $f=100 \mathrm{~Hz}$, SW amplitude $E_{\mathrm{sw}}=50 \mathrm{mV}$, and potential scan increment $\mathrm{d} E=1 \mathrm{mV}$, and scan rate $=100 \mathrm{mV} \mathrm{s}^{-1}$. 
where the formal potential $E_{\mathrm{c}}^{\ominus^{\prime}}$ can be defined as:

$$
\begin{aligned}
E_{\mathrm{c}}^{\ominus^{\prime}}= & E_{\mathrm{dmfc}^{+}{ }_{(\mathrm{NB})}}^{\ominus}\left[\mathrm{dmfc}_{(\mathrm{NB})}+\Delta_{\mathrm{W}}^{\mathrm{NB}} \varphi_{\mathrm{X}^{-}}^{\ominus}-\frac{R T}{F} \ln \left(a_{\mathrm{X}^{-}{ }_{(\mathrm{W})}}\right)\right. \\
& +\frac{R T}{F} \ln \left(\frac{a_{\mathrm{dmfc}_{(\mathrm{NB})}}^{*}}{2}\right)
\end{aligned}
$$

Here, $E_{\mathrm{dmfc}^{+}(\mathrm{NB})}^{\ominus} \mid \operatorname{dmfc}_{(\mathrm{NB})}$ is the standard potential of the $\mathrm{dmfc}^{+} /$ dmfc redox couple in nitrobenzene, $\Delta_{\mathrm{W}}^{\mathrm{NB}} \varphi_{\mathrm{X}^{-}}^{\ominus}$ is the standard potential of the transfer of $\mathrm{X}^{-}$from water to nitrobenzene, and $a^{*}{ }_{\mathrm{dmfc}}$ is the initial activity of dmfc in the organic phase. $E_{\mathrm{c}}^{\ominus^{\prime}}$ can be derived from the cyclic voltammograms as $E_{\mathrm{c}}^{\theta^{\prime}}=\frac{1}{2}\left(E_{\mathrm{p}, \mathrm{a}}+E_{\mathrm{p}, \mathrm{c}}\right)$, where $E_{\mathrm{p}, \mathrm{a}}$ and $E_{\mathrm{p}, \mathrm{c}}$ are the anodic and cathodic peak potentials, respectively, or from square-wave voltammograms according to $E_{\mathrm{c}}^{\bullet^{\prime}}=E_{\mathrm{p}, \mathrm{swv}}$, where $E_{\mathrm{p}, \mathrm{swv}}$ is the peak potential of the square-wave voltammograms. ${ }^{32}$ Knowing the standard transfer potential of the anion, one can calculate the standard Gibbs energy of transfer across the water|nitrobenzene interface using eqn. (3):

$$
\Delta G_{\mathrm{X}^{-}(\mathrm{W} \rightarrow \mathrm{NB})}^{\ominus}=-z F \Delta_{\mathrm{W}}^{\mathrm{NB}} \varphi_{\mathrm{X}^{-}}^{\ominus}
$$

(for mono-valent anions, $z$ is -1 ). The Galvani potential difference $\Delta_{\mathrm{W}}^{\mathrm{NB}} \varphi_{\mathrm{X}^{-}}^{\ominus}$ is defined as $\Delta_{\mathrm{W}}^{\mathrm{NB}} \varphi_{\mathrm{X}^{-}}^{\ominus}=\phi^{\mathrm{NB}}-\phi^{\mathrm{W}}$, where $\phi^{\mathrm{NB}}$ and $\phi^{\mathrm{W}}$ are the inner potentials of nitrobenzene and water, respectively. A study of the dependence of the voltammetric peak potentials (or mid-peak potentials in CV) on the logarithm of the concentration of the studied ions in the aqueous phase (see eqn. (2)) serves as a simple indicator whether the ion transfer process is in agreement with the theoretical Nernst dependence. $^{25,26,28,31,33}$ The voltammograms in Fig. 1 show clearly that there is no detectable $I R$-drop, although there is no electrolyte in the organic phase. That is because the nitrobenzene drop attains a high conductivity due to reaction (I) exactly in the region where the reaction takes place. ${ }^{34}$ Moreover, to understand correctly the three-phase electrode reactions, it is important to realize that the liquid-liquid interface (droplet-aqueous solution) is not polarized directly by the electric circuit but indirectly due to the electrochemical formation of the $\mathrm{dmfc}^{+} \mathrm{X}^{-}$salt inside the droplet. It is worth noting that this approach for studying the coupled electron and ion transfer across the interface of two immiscible solvents considerably differs from that of Anson et al. ${ }^{35-40}$ First, in our approach, a three-phase junction exists, i.e. the electrode surface is not completely covered with an organic film, as in the case of Anson's experiments. Second, the Anson experiments operate only in the case of a sufficient ionic conductivity of the organic film (see also the recent results of Aoki et al ${ }^{41}$ ) That can be provided by deliberately dissolving an electrolyte in the organic solvent, or by free partition of some rather hydrophobic salts (e.g. organic perchlorates) present initially in the aqueous phase. If Anson's approach were used to try to transfer an anion $\mathrm{A}^{-}$from water to the organic film, one would need to have at least an organic perchlorate in the aqueous phase to achieve film conductivity. If $\mathrm{A}^{-}$is more hydrophobic than perchlorate it would enter the organic filmvia free partition and it could be only expelled by reduction of a previously oxidized amount of dmfc. From the reduction potential it will not be easily possible to deduce the standard potential of ion transfer because the activity of $\mathrm{A}^{-}$due to free partition is not known. If $\mathrm{A}^{-}$is less hydrophobic than perchlorate it could not be transferred at all. In principle the same restrictions exist when a salt is deliberately dissolved in the organic phase. This means that Anson's approach cannot be used for the purpose of determination of the Gibbs energies of ion transfer. In light of the above discussion, the majority of Anson's works are concerned with the determination of the kinetics of electron transfer across the interface of two immiscible solvents (see for example refs. 36,37,39,40).

Table 1 summarizes the experimentally determined data of all studied anions. The reliability of the data determined by the three-phase electrode technique can be seen from the following comparisons of known data with those determined by us: i.e: $\Delta G^{\ominus}\left(\mathrm{ClO}_{3}{ }^{-}\right)=25.40 \mathrm{~kJ} \mathrm{~mol}^{-1}$ (from our experiment), $\Delta G^{\ominus}\left(\mathrm{ClO}_{3}{ }^{-}\right)=26.00 \mathrm{~kJ} \mathrm{~mol}^{-1}$ (from ref. 6), $\Delta G^{\ominus}\left(\mathrm{IO}_{3}{ }^{-}\right)=$ $32.40 \mathrm{~kJ} \mathrm{~mol}^{-1}$ (from our experiment), $\Delta G^{\ominus}\left(\mathrm{IO}_{3}{ }^{-}\right)=34.00$ $\mathrm{kJ} \mathrm{mol}^{-1}$ (from ref. 6), $\Delta G^{\ominus}\left(\mathrm{BrO}_{3}^{-}\right)=30.90 \mathrm{~kJ} \mathrm{~mol}^{-1}$ (from our experiment), $\Delta G^{\ominus}\left(\mathrm{BrO}_{3}{ }^{-}\right)=33 \mathrm{~kJ} \mathrm{~mol}^{-1}$ (from ref. 6), $\Delta G^{\ominus}\left(\mathrm{H}_{3} \mathrm{C}\left(\mathrm{CH}_{2}\right)_{8} \mathrm{COO}^{-}\right)=13.60$ (from our experiment), $\Delta G^{\ominus}\left(\mathrm{H}_{3} \mathrm{C}\left(\mathrm{CH}_{2}\right)_{8} \mathrm{COO}^{-}\right)=16.00 \mathrm{~kJ} \mathrm{~mol}^{-1}$ (from ref. 50), etc. Table 1 contains the formal potentials of the square-wave voltammograms (for $1 \mathrm{~mol} \mathrm{~L}^{-1}$ concentration of anions in aqueous solution), the slope of the formal potentials versus anion concentration in water, the calculated standard Gibbs energies of ion transfer and the standard deviation of the latter data. The data in Table 1 have been estimated using the previously determined value of the standard potential of $\mathrm{dmfc}^{+} /$ $\mathrm{dmfc}$ in nitrobenzene $(-0.184 \mathrm{~V}$ vs. $\mathrm{Ag} / \mathrm{AgCl}$ (sat. $\mathrm{NaCl})$ ). The latter value was determined as the intercept of the calibration graph of SW formal potentials of dmfc recorded in the three-phase arrangement $v s$. the standard potential of transfer of anions with known Gibbs energies of transfer (i.e. $\mathrm{ClO}_{4}{ }^{-}$, $\left.\mathrm{CNS}^{-}, \mathrm{Cl}^{-}, \mathrm{I}^{-}, \mathrm{NO}_{3}{ }^{-}\right){ }^{6}$ This is the right point to stress that the results obtained with the three-phase electrode technique rely on the Grunwald assumption, ${ }^{42}$ as does the results obtained with the conventional four-electrode technique.

In all cases cyclic voltammograms were recorded with different scan rates $\left(20\right.$ to $\left.500 \mathrm{mV} \mathrm{s}^{-1}\right)$ to compare the responses with those obtained by square-wave voltammetry. In all cases both methods gave essentially the same data, however, the square-wave voltammograms are superior with respect to reproducibility of formal potentials. Most probably this is due to the rather short perturbation caused by this technique. Unlike in previous studies with the dropping electrolyte electrode (four-electrode technique) ${ }^{23}$ we could obtain reliable data for the ions $\mathrm{ClO}_{3}{ }^{-}, \mathrm{BrO}_{3}{ }^{-}, \mathrm{IO}_{3}^{-}, \mathrm{IO}_{4}^{-}$and $\mathrm{CN}^{-}$. The slopes of peak potentials versus concentration of anions present in the aqueous phase serve as proof that the transfer of the studied anions occurs as depicted in Fig. 1. The slopes are very near to the theoretical value, with the exception of two cases i.e. monobromoacetate and $\mathrm{SeCN}^{-}$, where the deviation is more than $10 \mathrm{mV}$. The standard deviation of the formal potential ranges from 1 to $8 \mathrm{mV}$, which means that the standard deviation of $\Delta G$ ranges from 0.1 to $0.8 \mathrm{~kJ} \mathrm{~mol}^{-1}$.

In Fig. 2 are shown correlations between the standard Gibbs energies of transfer of different cyanate and halogenate ions and their reciprocal ionic radii (ionic radii have been taken from ref. 6). The linear relationships are in agreement with the simple electrostatic Born theory. ${ }^{1}$ It is interesting to stress that although the radii in the series of $\mathrm{Cl}^{-}, \mathrm{Br}^{-}$, and $\mathrm{I}^{-}$ increase in the order as written, the radii of $\mathrm{XO}_{3}{ }^{-}$decrease in the same direction. It is worth noting here that although several attempts have been made for modifying the simple electrostatic Born theory, e.g. dividing the Gibbs energy into charge dependent and charge independent terms (the latter one is connected with the energy needed for making a cavity in the solvent to accommodate a particular solute) and taking into account hydrated (not the crystal radii) of the ions (see for example Osakai's theory in refs. 1 and 43), non of these models is sufficiently precise to explain the exact behaviour of an ion in solution. Further theoretical studies seem to be required to establish an analytical equation of $\Delta G_{\mathrm{tr}}$ by which the Born equation (or its modification) can be replaced.

The standard Gibbs energies of transfer of the halogen substituted acetic acids decrease for each halogen from the mono- to the tri-substituted acetate. For the mono-halogen substituted acetic acids it was possible to calculate the radii from their densities and molecular weights by assuming that they have a spherical shape. Plotting the standard Gibbs energies of transfer of the ions versus the reciprocal radii did not give a linear relation. However, plotting the data versus $E / r$, 
Table 1 Formal potentials $E_{\mathrm{C}}^{\bullet^{\prime}}$, slope of $E_{\mathrm{C}}^{\bullet^{\prime}}$ versus concentration of anions in aqueous phase, standard deviation of peak potentials, standard Gibbs energies of ion transfer $\Delta G^{\ominus}$, and standard deviation of Gibbs energies of all studied anions

\begin{tabular}{|c|c|c|c|c|c|}
\hline Anion $^{a}$ & $E_{\mathrm{c}}^{\bullet^{\prime}}(v s . \mathrm{Ag} / \mathrm{AgCl}) / \mathrm{mV}$ & Slope $E_{\mathrm{c}}^{\bullet^{\prime}} v s . \log (c) / \mathrm{mV}$ & $s\left(E_{\mathrm{c}}^{\ominus^{\prime}}\right) / \mathrm{mV}^{b}$ & $\Delta G^{\ominus} / \mathrm{kJ} \mathrm{mol}^{-1}$ & $s\left(\Delta G^{\ominus}\right) / \mathrm{kJ} \mathrm{mol}^{-1 c}$ \\
\hline $\mathrm{ClO}_{3}{ }^{-}$ & 2 & -55.3 & 6.4 & 25.40 & 0.64 \\
\hline $\mathrm{BrO}_{3}^{-}$ & 60 & -58.7 & 7.1 & 30.90 & 0.71 \\
\hline $\mathrm{IO}_{3}^{-}$ & 74 & -54.3 & 8.0 & 32.40 & 0.80 \\
\hline $\mathrm{IO}_{4}^{-}$ & -132 & -56.4 & 2.0 & 12.50 & 0.19 \\
\hline $\mathrm{OCN}^{-}$ & 45 & -50.5 & 2.4 & 29.50 & 0.23 \\
\hline $\mathrm{SeCN}^{-}$ & -136 & -43.0 & 5.3 & 11.80 & 0.53 \\
\hline $\mathrm{CN}^{-}$ & 41 & -58.1 & 4.4 & 29.60 & 0.45 \\
\hline $\mathrm{N}_{3}^{-}$ & 14 & -52.1 & 3.4 & 26.80 & 0.35 \\
\hline Monofluoroacetate & 44 & -54.4 & 5.4 & 29.90 & 0.54 \\
\hline Difluoroacetate & 34 & -48.5 & 3.9 & 28.90 & 0.38 \\
\hline Trifluoroacetate & -2 & -60.1 & 1.7 & 25.30 & 0.18 \\
\hline Monochloroacetate & 36 & -51.5 & 4.7 & 29.10 & 0.48 \\
\hline Dichloroacetate & 9 & -58.0 & 1.1 & 26.40 & 0.10 \\
\hline Trichloroacetate & -66 & -60.1 & 1.9 & 18.80 & 0.20 \\
\hline Monobromoacetate & 12 & -39.3 & 3.4 & 26.70 & 0.35 \\
\hline Dibromoacetate & -7 & -59.0 & 2.0 & 24.80 & 0.20 \\
\hline Tribromoacetate & -94 & -59.8 & 1.0 & 16.00 & 0.10 \\
\hline Monoiodoacetate & 0 & -54.6 & 1.2 & 25.10 & 0.10 \\
\hline $\mathrm{HCOO}^{-}$ & 58 & -56.4 & 2.4 & 30.60 & 0.23 \\
\hline $\mathrm{H}_{3} \mathrm{CCOO}^{-}$ & 52 & -58.0 & 1.5 & 30.10 & 0.13 \\
\hline $\mathrm{H}_{3} \mathrm{CCH}_{2} \mathrm{COO}^{-}$ & 29 & -54.6 & 0.8 & 27.98 & 0.10 \\
\hline $\mathrm{H}_{3} \mathrm{C}\left(\mathrm{CH}_{2}\right)_{2} \mathrm{COO}^{-}$ & 11 & -53.1 & 2.2 & 26.25 & 0.21 \\
\hline $\mathrm{H}_{3} \mathrm{C}\left(\mathrm{CH}_{2}\right)_{3} \mathrm{COO}^{-}$ & -31 & -63.5 & 2.8 & 22.30 & 0.26 \\
\hline $\mathrm{H}_{3} \mathrm{C}\left(\mathrm{CH}_{2}\right)_{4} \mathrm{COO}^{-}$ & -75 & -60.3 & 1.4 & 18.10 & 0.12 \\
\hline $\mathrm{H}_{3} \mathrm{C}\left(\mathrm{CH}_{2}\right)_{5} \mathrm{COO}^{-}$ & -115 & -55.2 & 1.8 & 14.20 & 0.16 \\
\hline $\mathrm{H}_{3} \mathrm{C}\left(\mathrm{CH}_{2}\right)_{6} \mathrm{COO}^{-}$ & -125 & -57.4 & 4.2 & 12.64 & 0.40 \\
\hline $\mathrm{H}_{3} \mathrm{C}\left(\mathrm{CH}_{2}\right)_{7} \mathrm{COO}^{-}$ & -120 & -52.9 & 3.2 & 13.40 & 0.30 \\
\hline $\mathrm{H}_{3} \mathrm{C}\left(\mathrm{CH}_{2}\right)_{8} \mathrm{COO}^{-}$ & -118 & -58.4 & 2.5 & 13.60 & 0.24 \\
\hline Cyclopropane carboxylate & -20 & -60.0 & 1.1 & 23.25 & 0.10 \\
\hline Cyclobutane carboxylate & -61 & -57.8 & 1.4 & 19.30 & 0.12 \\
\hline Cyclopentane carboxylate & -100 & -63.2 & 1.6 & 15.54 & 0.15 \\
\hline Cyclohexane carboxylate & -131 & -56.8 & 2.8 & 12.54 & 0.26 \\
\hline Cycloheptane carboxylate & -155 & -55.4 & 2.0 & 10.22 & 0.19 \\
\hline
\end{tabular}

${ }^{a}$ Six measurements have been performed for one concentration of each anion. ${ }^{b} s\left(E_{\mathrm{C}}^{\ominus^{\prime}}\right)$ is the standard deviation of the SW formal potential. $s\left(\Delta G^{\ominus}\right)$ is the standard deviation of the Gibbs energy.

where $r$ is the radius of the acid molecule and $E$ is the electronegativity of the halogen substituent, gives a linear relation (cf. Fig. 3). The effect of increasing electronegativity can be explained as follows: first it will decrease the charge on the carboxylate group, causing a weaker ion-dipole interaction with water and hence a smaller enthalpy of hydration. Second, the weaker hydration leads also to a smaller entropy gain when the ion is being transferred to nitrobenzene. This entropy effect may be more important than the enthalpy effect, thus stabiliz-

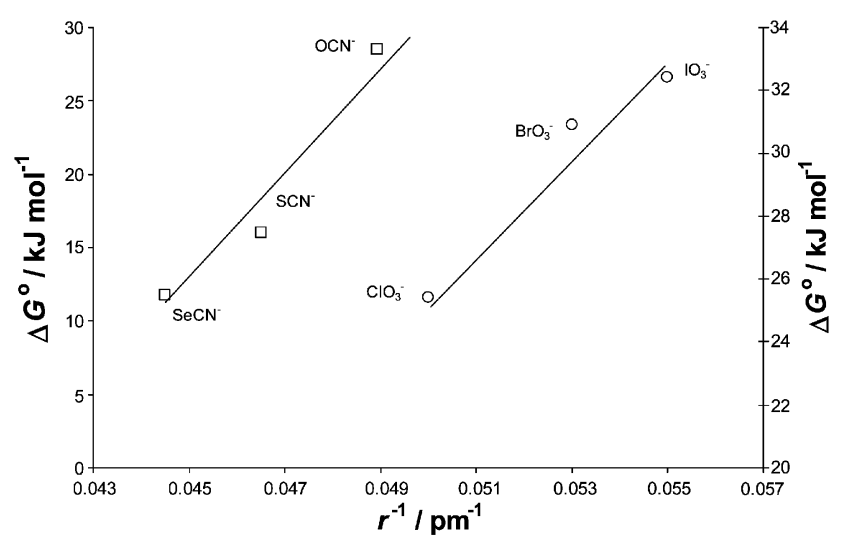

Fig. 2 Dependence of the experimentally determined $\Delta G^{\ominus}$ values at the three-phase electrode on the inverse ionic radii of different cyanate and halogenate anions. (Values for the ionic radii are from ref. 6). ing the halogen acetate ions in water with increasing electronegativity of the halogen substituents. This explanation is completely in line with the discussion of the acidity constants of the halogen substituted acetic acids. ${ }^{44}$

Fig. 4 shows a comparison of the Gibbs free energies of ion transfer of the n-alkyl and of cyclocarboxylate anions. The

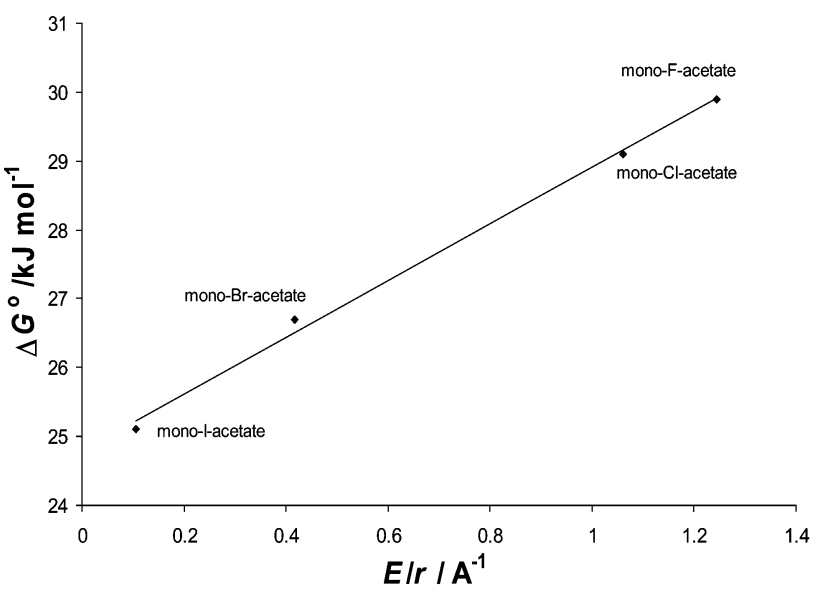

Fig. 3 Dependence of the experimentally determined $\Delta G^{\ominus}$ values at the three phase electrode on electronegativities $E$ of the halogen substituents, divided by the molecular radii of the mono-substituted halogen substituted acids. 


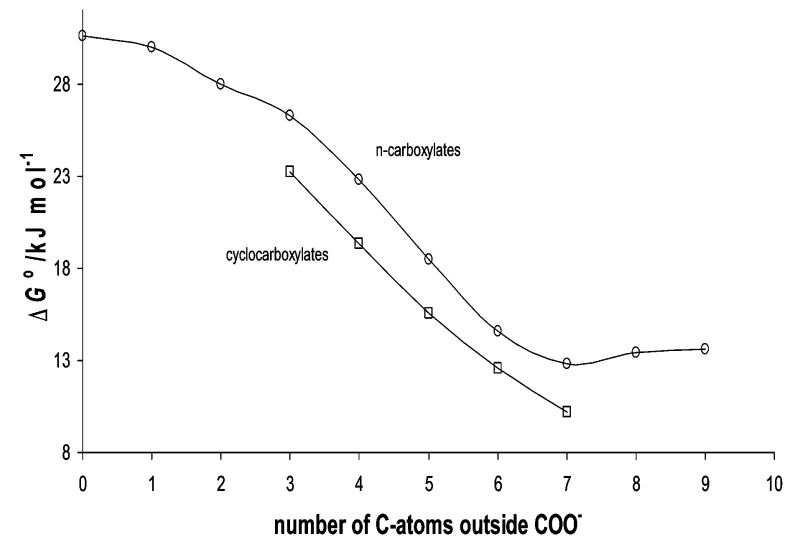

Fig. 4 Comparison of the dependence of standard Gibbs energies of transfer of n-alkyl and cyclocarboxylate ions for the system waternitrobenzene.

data for n-alkyl carboxylate are published elsewhere. ${ }^{28}$ From Fig. 4 follows that for the same number of carbon atoms the standard Gibbs energies of transfer are about $3 \mathrm{~kJ} \mathrm{~mol}^{-1}$ larger for the chain than for the ring anions. This cannot be understood by considering the hydrophobic effect because the chain ions have a larger surface area than the ring ions. The hydrophobic effect, i.e. the formation of the so-called iceberg structure around hydrophobic molecules ${ }^{45,46}$ will be proportional to the surface area of the molecules. Thus it must be expected that the hydrophobicity of the chain ions should be larger than that of the ring ions, which is clearly opposite to the experimental data. Also, the small differences in the molecular volumes of the chain and ring ions cannot account for these differences in Gibbs energies. A possible explanation is that the rings are more strongly solvated by nitrobenzene than the chains. It is worth noting that the addition of a methylene $\mathrm{CH}_{2}$ group in the cyclo-rings lowers the value of $\Delta G^{\ominus}$ by about $3.5 \mathrm{~kJ} \mathrm{~mol}^{-1}$. The same energetic contribution upon addition of a $\mathrm{CH}_{2}$ group has been found for the transfer of $\mathrm{n}$-alkanes from water to n-hexane, ${ }^{47} \mathrm{n}$-alkyl alcohols from water to alcohol ${ }^{48}$ and alkylcyclocarboxylic acids from water to n-heptane, ${ }^{49}$ and also in a previous electrochemical study with the dropping electrolyte electrode. ${ }^{50}$

In the case of the ions $\mathrm{HSO}_{3}{ }^{-}, \mathrm{HSO}_{4}^{-}, \mathrm{HCO}_{3}{ }^{-}, \mathrm{HS}^{-}$, $\mathrm{H}_{2} \mathrm{PO}_{4}^{-}, \mathrm{NO}_{2}^{-}, \mathrm{OH}^{-}$, slopes of $E_{\mathrm{p}}$ vs. logarithm of $c$ (concentration of these ions in the water phase) have been observed, that cannot be explained on the basis of an ion transfer from the aqueous to the organic phase. The slopes were between 0 and $30 \mathrm{mV}$ per decade of concentration. These data, taken together with unstable cyclic voltammograms during consecutive cycling, indicate that the oxidation of dmfc in nitrobenzene is followed by the transfer of the formed $\mathrm{dmfc}^{+}$ions from nitrobenzene to water. This reaction always occurs when the standard Gibbs energy of transfer of the anions from water to $\mathrm{NB}$ is larger than that of $\mathrm{dmfc}^{+}$from NB to water.

\section{Conclusions}

The reported data add to our knowledge of Gibbs transfer energies of simple and important anions involved in natural, technical and analytical phase transfer processes. In case of the mono-halogen substituted acetate anions, for the first time, a linear correlation was found between the standard Gibbs energies of transfer and the ratios of electronegativities for halogens to the radii of the acetate anions. Although the presented dependencies of Gibbs energies of transfer of ions on ion properties give clear indication of the involved effects, a quantitative understanding will need detailed measurements of the enthalpies and entropies of the ion transfer, spectroscopic studies of the solvation of the ions in both solvents (taking into account the rather high concentration of water in the organic phase, and vice versa), and molecular modeling of the solvated ions.

\section{Acknowledgements}

F. Scholz acknowledges support by Deutsche Forschungsgemeinschaft (DFG) and Fonds der Chemischen Industrie (FCI), R. Gulaboski thanks Deutscher Akademischer Austauschdienst (DAAD) for provision of a $\mathrm{PhD}$ scholarship.

\section{References}

1 A. G. Volkov, in Liquid Interfaces in Chemical, Biological and Pharmaceutical Applications, Marcel Dekker, New York, Basel, 2001.

2 H. H Girault and D. J. Schiffrin, in Electroanalytical Chemistry, ed. A. J. Bard, vol. 15, Marcel Dekker, New York, 1989.

3 C. Hansch, J. E. Quinlan and G. L. Lawrence, J. Org. Chem., 1968, 33, 347-354.

4 A. Leo, C. Hansch and D. Elkins, Chem. Soc. Rev., 1971, 71, 525-616.

5 B. Testa, G. Caron, P. Crivori, S. Rey, M. Reist and P.- A. Carrupt, Chimia, 2000, 54, 672-677.

6 Y. Marcus,Ion Properties, Marcel Dekker, New York, 1997, p. 212-219.

7 S. Wilke, Habilitation Thesis, Martin-Luther Universität Halle (Saale), 2002.

8 S. Wilke and T. Zerihun, Electrochim. Acta, 1998, 44, 15-22.

9 G. Taylor and H. H. Girault, J. Electroanal. Chem., 1986, 208, 179-183.

10 M. D. Osborne, Y. Shao, C. M. Pereira and H. H. Girault, J. Electroanal. Chem., 1994, 364, 155-162.

11 A. Campbell and H. H. Girault, J. Electroanal. Chem., 1989, 266, 465-469.

12 S. Wilke and H. Wang, J. Electroanal. Chem., 1999, 475, 9-19.

13 B. Hundhammer, T. Solomon, T. Zerihun, M. Abegaz, A. Bekele and K. Graichen, J. Electroanal. Chem., 1994, 371, 1-11.

14 S. Wilke and T. Zerihun, J. Electroanal. Chem., 2002, 515, 52-60.

15 A. J. Christoffels, F. de Jong and D. N. Reinhoud, Chem. Eur. J., 2000, 6, 1376-1385

16 O. Valent, J. Koryta and M. Panoch, J. Electroanal. Chem., 1987, 226, 21-25.

17 S. Wilke and H. Wang, J. Electroanal. Chem., 1999, 475, 9-19.

18 D. Homolka, K. Holub and V. Marecek, J. Electroanal. Chem., 1982, 138, 29-36.

19 F. Reymond, G. Lagger, P.-A. Carrupt and H. H. Girault, J. Electroanal. Chem., 1998, 451, 59-76.

20 F. Reymond, G. Lagger, P.-A. Carrupt and H. H. Girault, J. Electroanal. Chem., 1998, 449, 49-65.

21 G. Bouchard, P.-A. Carrupt, B. Testa, V. Gobry and H. H. Girault, Chem. Eur. J., 2002, 8, 1-7.

22 V. Chopineaux-Courtois, F. Reymond, G. Bouchard, P.-A Carrupt., B. Testa and H. H. Girault, J. Am. Chem. Soc., 1999, 121, 1743-1747.

23 S. Kihara, M. Suzuki, K. Maeda, K. Ogura and M. Matsui, J. Electroanal. Chem., 1986, 210, 147-159.

24 F. Scholz, S. Komorsky-Lovrić and M. Lovrić, Electrochem. Commun., 2000, 2, 112-118.

25 R. Gulaboski, V. Mirčeski and F. Scholz, Electrochem. Commun., 2002, 4, 277-283.

26 R. Gulaboski, V. Mirčeski and F. Scholz, Amino Acids, in press, (DOI: 10.1007/s00726-002-0320-x).

27 M. Donten, Z. Stojek and F. Scholz, Electrochem. Commun., 2002, 4, 324-328.

28 S. Komorsky-Lovrić, K. Riedl, R. Gulaboski, V. Mirčeski and F. Scholz, Langmuir, 2002, 18, 8000-8005.

29 F. Scholz, R. Gulaboski, V. Mirčeski and P. Langer, Electrochem. Commun., 2002, 4, 659-662.

30 F. Scholz and B. Meyer in Electroanalytical Chemistry. A Series of Advances, eds. A. J. Bard and I. Rubinstein, vol. 20, Marcel Dekker, New York, 1998 pp. 1-82.

31 Š. Komorsky-Lovrić, M. Lovrić and F. Scholz, J. Electroanal. Chem., 2001, 508, 129-137. 
32 M. Lovrić, in Electroanalytical methods, Guide to experiments and applications, ed. F. Scholz, Springer-Verlag, Berlin and Heidelberg, 2002, pp. 111-133.

33 S. Komorsky-Lovrić, M. Lovrić and F. Scholz, Collect. Czech. Chem. Commun., 2001, 66, 434 444.

34 M. Lovric and F. Scholz, J. Electroanal. Chem., 2003, 540, 89-96.

35 C. Shi and C. Anson., Anal. Chem., 1998, 70, 3114-3118.

36 C. Shi and C. Anson., J. Phys. Chem. B, 1998, 102, 9850-9854.

37 C. Shi and F. C. Anson., J. Phys. Chem.B, 1999, 103, 6283-6289.

38 T. D. Chung and F. C. Anson, Anal. Chem., 2001, 73, 337-342.

39 C. Shi and C. Anson, J. Phys. Chem., 2001, 105, 1047-1049.

40 C. Shi and C. Anson., J. Phys. Chem. B, 2001, 105, 8963-8969.

41 P. Tasakorn, J. Chen and K. Aoki, J. Electroanal. Chem., 2002, 533, 119-126.
42 E. Grunwald, G. Baughman and G. Kohnstam, J. Am. Chem. Soc., 1969, 82, 5801

43 T. Osakai, A. Ogata and K. Ebina, J. Phys. Chem. B, 1997, 101, 8341-8348.

44 P. Sykes, Reaktionsmechanismen der Organischen Chemie, VCH, Weinheim, 9th edn., 1988, p. 68.

45 H. S. Frank and M. W. Evans, J. Chem. Phys., 1945, 13, 507-532.

46 N. Muller, Acc. Chem. Res., 1990, 23, 23-28.

47 M. H. Abraham, J. Am. Chem. Soc., 1982, 104, 2085.

48 C. Tanford, The Hydrophobic Effect, Wiley, New York, 2nd edn., 1979.

49 R. Smith and C. Tanford, Proc. Natl. Acad. Sci. USA, 1973, 70, 289.

50 S. Kihara, M. Suzuki, M. Sugiyama and M. Matsui, J. Electroanal. Chem., 1988, 249, 109-122. 